\title{
Internet-based asthma education - A novel approach to compliance: A case report
}

\author{
Cindy $\mathrm{O}^{\prime}$ Hara $\mathrm{RN}$ OHN CAE${ }^{1}$, Dilini Vethanayagam $\mathrm{MD}^{2}$, Carina Majaesic $M D^{3}$, Irvin Mayers $\mathrm{MD}^{2}$
}

\begin{abstract}
C O’Hara, D Vethanayagam, C Majaesic, I Mayers. Internetbased asthma education - A novel approach to compliance: A case report. Can Respir J 2006;13(1):30-32.
\end{abstract}

\begin{abstract}
Asthma costs Canadians over $\$ 1.2$ billion per annum and, despite advances, many asthmatic patients still have poor control. An action plan, symptom diary and measurement of peak expiratory flow have been shown to improve clinical outcomes. Effective educational interventions are an important component of good care. However, many rural sites lack not only access to education but physician care as well. It is reasonable, therefore, that an Internetbased asthma management program may be used as an approach. In the present case report, a novel approach that may increase access in these poorly serviced areas is presented. In an Internet-based asthma management program, patients are reviewed by a physician, receive education and are given a unique password that provides program access. Patients record symptoms and peak expiratory flow rates. The present case report shows that a patient can be assisted through an exacerbation, thus averting emergency intervention and stabilizing control, even when travelling on another continent.
\end{abstract}

Key Words: Action plan; Asthma; Education; Internet; Peak flow monitoring; Symptom diary

$\mathrm{O}$ verall, asthma costs Canadians over $\$ 1.2$ billion per annum (1) and, despite advances, many asthmatic patients still have poor control. The use of written action plans has resulted in improved outcomes (2-4). Effective educational interventions can reduce asthma-related health care services use and improve patients' knowledge about their disease and, thus, improve compliance (5). Often, factors such as limited geographical access can constitute a barrier to good care (6). However, few interventions, if any, have used Internet technology to address asthma management. Although there are over $90 \mathrm{Web}$ sites directed at providing asthma education, they do not provide interactive asthma management (7). A Medline search revealed only one relevant publication concerning this technology and, to date, we are not aware of any ongoing Internet-based approach to the treatment of asthma. The present case report highlights the utility that an Internetbased asthma management system can have to successfully support patients who are geographically compromised. The patient discussed in the present report responded to the

\section{Rapport de cas : Le cyberenseignement, une approche novatrice pour promouvoir l'observance du traitement de l'asthme}

\begin{abstract}
L'asthme coûte annuellement plus de 1,2 milliard de dollars aux Canadiens et malgré les progrès réalisés, chez de nombreux patients, la maladie n'est toujours pas adéquatement contrôlée. L'application d'un plan d'action, la tenue d'un carnet des symptômes et la mesure du débit expiratoire de pointe ont donné de bons résultats cliniques. Et les interventions axées sur l'enseignement au patient sont un autre important élément du traitement. Par contre, en région éloignée, l'enseignement et l'accès aux médecins font souvent défaut. Il est donc envisageable de recourir à un cyberprogramme de prise en charge de l'asthme pour compenser ces lacunes. Dans le présent rapport de cas, on propose une nouvelle approche pour favoriser l'accès des régions éloignées à ce type de service. Dans le cadre d'un cyberprogramme de prise en charge de l'asthme, les cas sont passés en revue par un médecin, les patients reçoivent un enseignement et on leur remet un mot de passe exclusif qui leur permet d'accéder au programme. Les patients y notent leurs symptômes et leurs débits expiratoires de pointe. Le présent rapport de cas montre qu'un patient peut même être soutenu pendant une crise d'asthme, ce qui évite les interventions d'urgence et assure un meilleur contrôle, même lors de déplacements sur d'autres continents.
\end{abstract}

Internet-based asthma support, as shown by documenting symptoms, medication use and peak expiratory flow (PEF) values on a daily basis.

The University of Alberta, Edmonton, Alberta, developed the virtual asthma clinic (VAC) in 2004. Following a medical evaluation, patients were referred to a certified asthma educator $(\mathrm{CAE})$ for education and monitoring. Inclusion criteria were a physician's diagnosis of asthma, including physiological evidence of reversibility or airway hyperresponsiveness to methacholine or exercise, disease stability, and access and willingness to use a computer and the Internet. The VAC provides a setting for patients to monitor their symptoms, medication use and PEF rate, and to have daily communication with a CAE. Those eligible are provided with a password that allows access to the VAC, which is on a secure Internet site that conforms to the 2004 Privacy Act in Alberta. In addition to individual education and CAE access, the VAC site also provides educational material on asthma and allergy, along with links to other asthma Web sites.

${ }^{1}$ Alberta Asthma Centre, Department of Medicine; ${ }^{2}$ Pulmonary Division, Department of Medicine; ${ }^{3}$ Department of Pediatrics, University of Alberta, Edmonton, Alberta

Correspondence: Ms Cindy O'Hara, Department of Medicine, University of Alberta, 11402 University Avenue, 2E4.01, Edmonton, Alberta T6G 2B7. Telephone 780-407-1636, fax 780-407-6384, e-mail cindyohara@cha.ab.ca 
The following case presentation discusses the assistance of a patient whose asthma control worsened while travelling on a vacation to Europe.

\section{CASE PRESENTATION}

A 69-year-old, active man was enrolled. He was an ex-smoker (33 pack-years) with asthma that had been diagnosed by a physcian three years prior; asthma was indicated by airway hyperresponsiveness and a 20\% reversibility of forced expiratory volume in $1 \mathrm{~s}\left(\mathrm{FEV}_{1}\right)$. He had no hospitalizations but reported being seen in the emergency department for asthma episodes on two occasions. He had documented acetylsalicylic acid sensitivity and chronic postnasal drip. His immediate family history was negative for asthma, allergy and eczema; however, both parents had been smokers. His home and occupational environments were benign. Allergy skin tests were positive for grass and house dust mites. He had no personal history of eczema. The remainder of his history was otherwise unremarkable.

Since his diagnosis of asthma, the patient has been reviewed in an asthma clinic setting every six months. On initial assessment, the patient took beclomethasone dipropionate (100 $\mu \mathrm{g}$; two puffs twice daily), salbutamol (two puffs as needed) and a nasal corticosteroid (one spray in each nostril twice daily); however, adherence to all medication was poor. Despite receiving asthma education by a CAE, being prescribed an inhaled corticosteroid and beta-agonist, and having a management plan, he continued to experience asthma symptoms more than three times per week, with $20 \%$ reversibility of $\mathrm{FEV}_{1}$ with salbutamol. On enrollment to the VAC, his asthma education was reinforced with a focus on management and prevention. His spirometry during periods of stability showed a normal forced vital capacity of $3.74 \mathrm{~L}$ (91\% predicted), an $\mathrm{FEV}_{1}$ of $2.59 \mathrm{~L}$ ( $81 \%$ predicted) and an $\mathrm{FEV}_{1} /$ forced vital capacity of $87 \%$ predicted. His personal best PEF was recorded at $570 \mathrm{~L} / \mathrm{min}$.

Despite having a self-management plan, the patient took his inhaled corticosteroids during exacerbations only. This inconsistency resulted in poor disease control. The patient agreed to participate in the VAC and received patient-centred asthma education and a written action plan, as well as the added benefits of daily contact with a CAE, access to asthma reference material and an on-line action plan advising him to adjust treatment in correlation to reported symptoms/PEF. The patient would enter his symptoms, peak flow values and medication use on a secure Internet-based asthma management system, where he and the nurse could monitor his control on a daily basis.

Because of poor compliance and symptoms, the patient was switched to a budesonide/formoterol combination inhaler. Twelve days after the patient entered the Internet-based asthma management program, he travelled to Europe for a holiday. Through the Web site, the patient was given access to a written action plan that provided medication adjustments based on PEF rates of $85 \%$ and $65 \%$ of the patients' personal best. In addition, the reporting of asthma symptoms (eg, beta-agonist use, shortness of breath and cough) was also taken into consideration, adjusting therapy if a symptom was reported more than three times per week.

On arriving in Europe, the patient communicated with the nurse that he had an increase in his asthma symptoms (ie, dyspnea, wheeze and an inability to carry out his usual activities), with a concomitant reduction in PEF (approximately

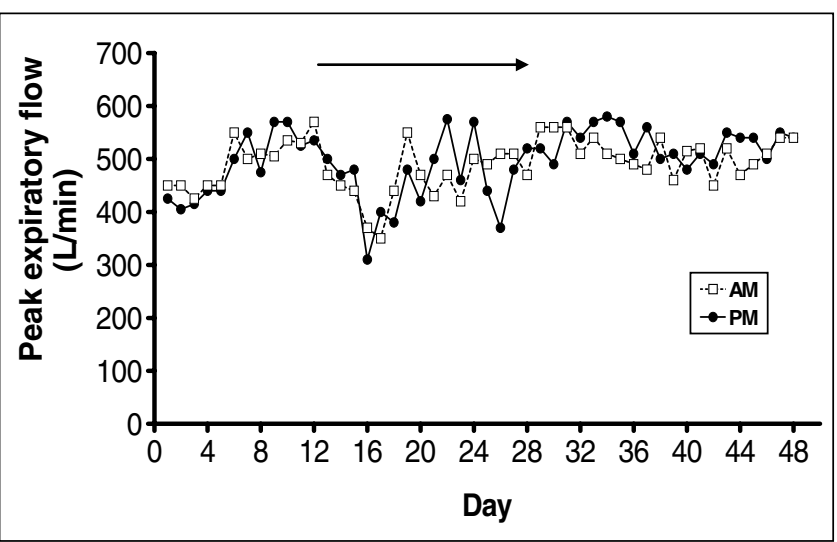

Figure 1) The peak expiratory flow for the patient over a course of 48 days. The arrow indicates when the patient was on holiday in Europe

20\%), which resulted in increased inhaled beta-agonist use. Figure 1 shows the course of morning and evening PEF values entered on-line by the patient. The nurse and Internet-based management system both guided the patient to double his medication and maintain this regimen until returning home. The early increase in medication may have obviated the need for any emergency intervention or loss of holiday time.

\section{DISCUSSION}

Evidence shows that asthma control can be improved and that this results in substantial savings in costs (as well as an improved quality of life for those with the disease). Cowie and Underwood (8) have data to support this outcome from a pilot study of 378 patients in which a $1 \mathrm{~h}$ to $1.3 \mathrm{~h}$ educational intervention resulted in a savings of $\$ 600,000$ in one year. This finding is supported by similar studies, which show that patient education results in improved quality of life, improved disease control, less time off work or school, and a substantial reduction in emergency department utilization and hospitalizations $(8,9)$. It is unreasonable, however, to expect that all asthmatic patients will learn optimal management through one educational method of delivery.

It is reasonable, therefore, to explore methods to use technology in an appropriately regulated manner (eg, addressing privacy, security and medical legal issues), much the same way as a nurse manages or guides patients with their asthma over the telephone or in person. The present case clearly shows that the Internet-based asthma clinic can safely triage a patient and also shows that a previously noncompliant patient with poor asthma control can respond to this mode of education, allowing him or her independence and understanding by using a relatable method. To date, our patient enjoys good asthma control.

Modern society is technology driven and supports an Internet-based patient management system; however, barriers to Internet access and associated costs (eg, privacy and legal implications) are still factors affecting widespread use, and must be kept in mind. However, we have shown that it is possible to successfully triage a patient who is geographically compromised.

\section{CONCLUSIONS}

It is important to assess patients for their readiness to receive information, and it is crucial to continue to explore methods to negotiate self-management, recognizing that one method 
does not suit all. Internet-based asthma management can be effective for a select group of patients. It can overcome geographical barriers and allow more effective and early intervention in the setting of exacerbations. The full scope of health care cost savings and other benefits of these types of management programs remain to be determined.

ACKNOWLEDGEMENT: The present work was funded by the Alberta Telehealth Fund, AstraZeneca Canada Inc and the Alberta Strategy to Help Manage Asthma (ASTHMA).

\section{REFERENCES}

1. Krahn MD, Berka C, Langlois P, Detsky AS. Direct and indirect costs of asthma in Canada, 1990. CMAJ 1996;154:821-31.

2. Abramson MJ, Bailey MJ, Couper FJ, et al; Victorian Asthma Mortality Study Group. Are asthma medications and management related to deaths from asthma? Am J Respir Crit Care Med 2001;163:12-8.

3. Adams RJ, Smith BJ, Ruffin RE. Factors associated with hospital admissions and repeat emergency department visits for adults with asthma. Thorax 2000;55:566-73.

4. Cowie RL, Revitt SG, Underwood MF, Field SK. The effect of a peak flow-based action plan in the prevention of exacerbations of asthma. Chest 1997;112:1534-8

5. Boulet LP, Bai TR, Becker A, et al. What is new since the last (1999) Canadian Asthma Consensus Guidelines? Can Respir J 2001;8(Suppl A):5A-27A.

6. Douglass J, Aroni R, Goeman D, et al. A qualitative study of action plans for asthma. BMJ 2002;324:1003-5.

7. Croft DR, Peterson MW. An evaluation of the quality and contents of asthma education on the World Wide Web. Chest 2002;121:1301-7.

8. Cowie RL, Underwood M. The effectiveness of a brief asthma education program in preventing exacerbations of asthma. Am J Respir Crit Care Med 1994;149:A251. (Abst)

9. Barnes PJ, Jonsson B, Klim JB. The costs of asthma. Eur Respir J 1996;9:636-42 


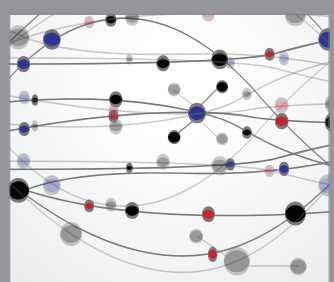

The Scientific World Journal
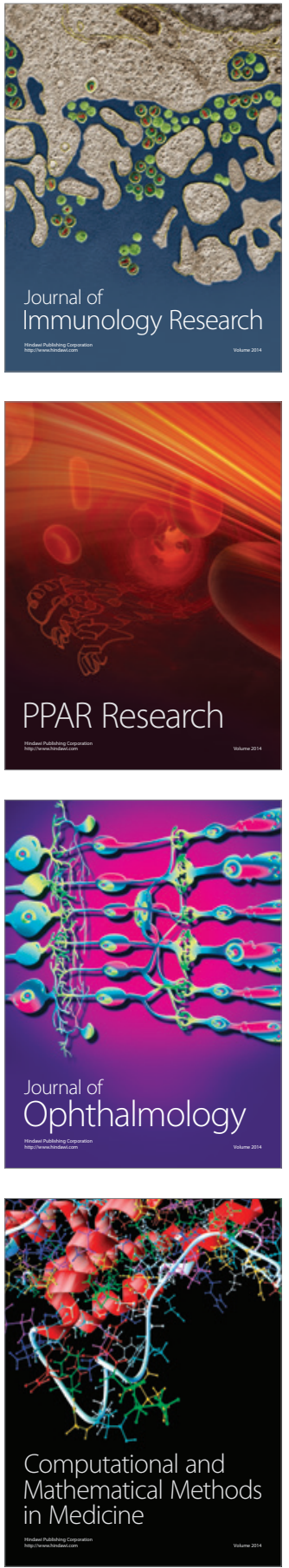

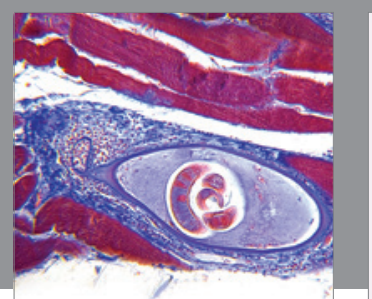

Gastroenterology Research and Practice

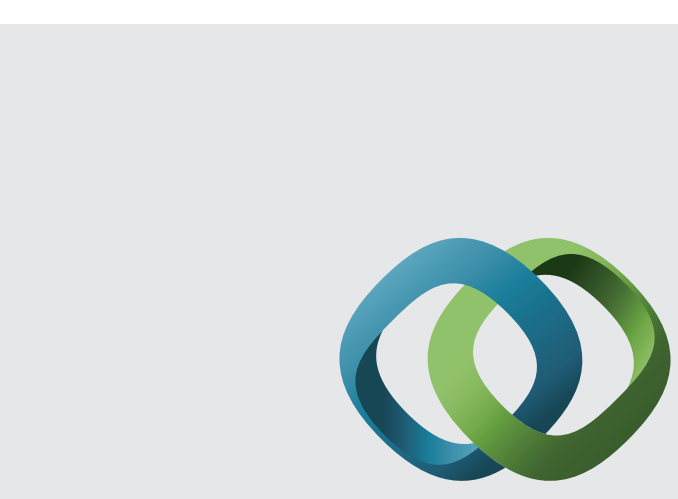

\section{Hindawi}

Submit your manuscripts at

http://www.hindawi.com
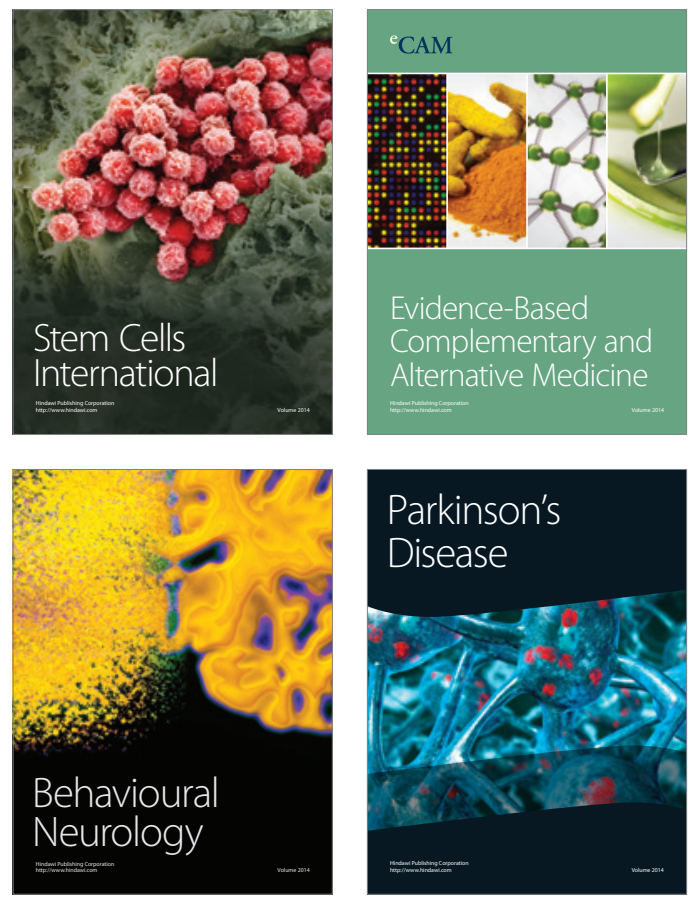
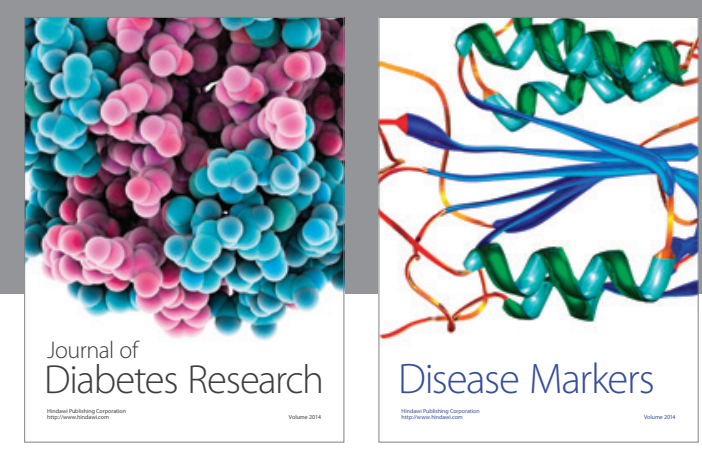

Disease Markers
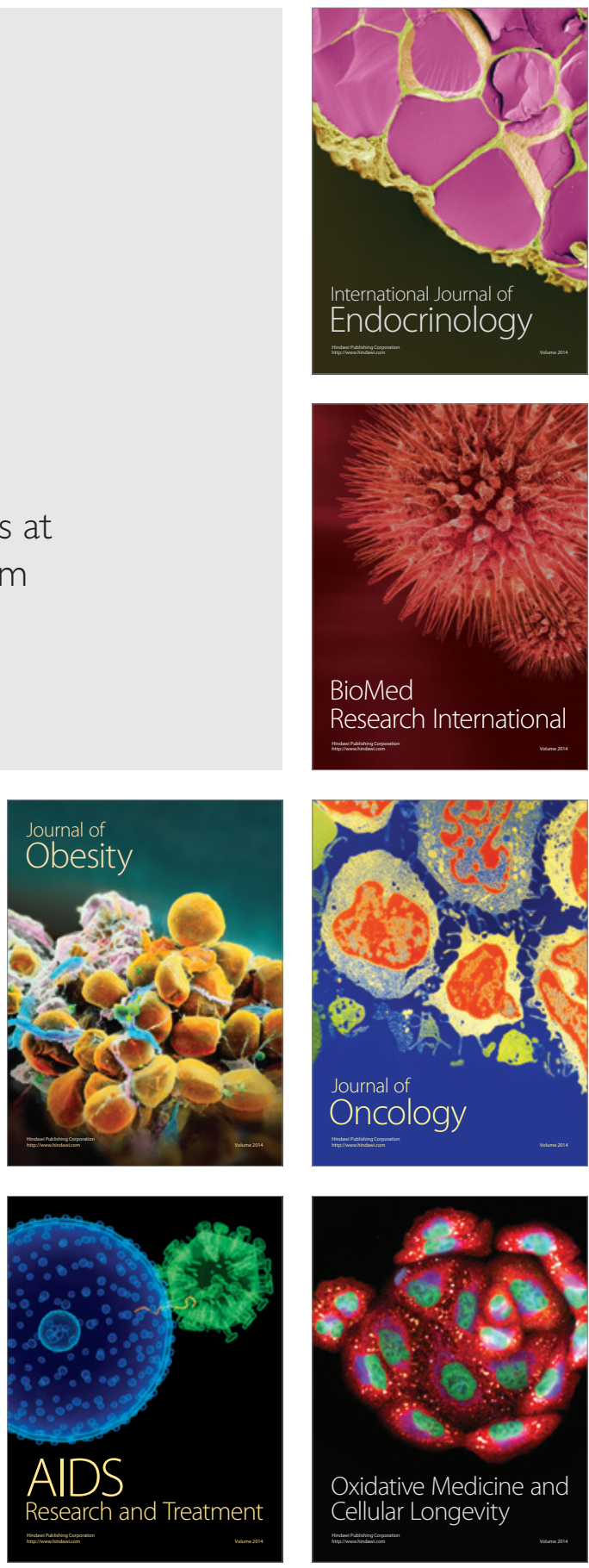